\title{
STUDY ON THE EFFECT OF GRANITE POWDER IN COCONUT SHELL CONCRETE MECHANICAL PROPERTIES
}

\author{
Dilip Yadav" and K. Gunasekaran \\ Department of Civil Engineering, \\ SRM Institute of Science and Technology, Kattankulathur, Tamilnadu, India - 603203 \\ *E-mail: deeleeep408@gmail.com
}

\begin{abstract}
In this study, Granite powder (GP) was used as a partial replacement for Ordinary Portland cement (OPC) in conventional concrete (CC) and coconut shell concrete (CSC) to explore the properties of concrete. OPC was replaced by GP in term of $0 \%, 5 \%, 10 \%, 15 \%, 20 \%$ and $25 \%$ for the optimization of percentage use in concrete mix. The density of concrete, workability and mechanical properties that are compressive strength, split tensile strength, flexural strength, modulus of elasticity and impact resistance strength were analyzed and contrasted with standard values with the optimized percentage of GP. As the compressive strength keeps on increasing with an increased percentage of GP till $10 \%$ both in CC and CSC. Hence the optimized percentage of GP was set at $10 \%$ for better workability and mechanical properties for both CC and CSC.
\end{abstract}

Keywords: Coconut Shell, Granite Powder, Partial Replacement, Lightweight Concrete, Mechanical Properties

(c) RASĀYAN. All rights reserved

\section{INTRODUCTION}

In the present scenario, many alternative materials are exploited for concrete production as this idea support in material conservation. Light weight concrete (LWC) is progressively getting popular in the present date with several advantages over traditional concrete ${ }^{1}$. Coconut shell (CS) is considered as one of the best light weight aggregates and many research works were already carried out on $\mathrm{CSC}^{2-5}$. In all research, conventional coarse aggregate (CCA) was replaced by coconut shell aggregate (CSA) and found better outcomes for LWC production. But in those research works, OPC was used as a binding material. Therefore, to diminish the use of OPC and to decrease $\mathrm{CO}_{2}$ emission, GP which is an industrial waste product can be replaced for cement so that the landfill of GP can be minimized to some extent and environmental pollution can be lessened too ${ }^{6-9}$. GP waste can be minimized by utilizing it as a partial replacement of OPC in CC and CSC. Subsequently, eco-friendly concrete can be produced by combining both GP and CS. Hence, in this investigation, the effect of GP in CC and CSC were studied on mechanical properties.

\section{Materials Used}

\section{EXPERIMENTAL}

Ordinary Portland cement of 53 grade having specific gravity 3.15 in compliance with IS $12269(1987)^{10}$ was used for both CC and CSC. River sand was used as a fine aggregate having a specific gravity of 2.62 as per IS 383: $2016^{11}$ for both CC and CSC. The conventional aggregate retained on $4.75 \mathrm{~mm}$ sieve, size about $12.5 \mathrm{~mm}$ in dry condition with a specific gravity of 2.66 was used as coarse aggregate in concrete preparation, confirming to IS 383: $2016^{11}$. Potable water meeting the requirements as per IS $456-2000^{12}$ was used for casting and curing of concrete specimen.

\section{Coconut Shell Aggregate}

Raw and fresh CS is collected from the local sources as shown in Fig.-1(a) and crushed using the coconut shell crushing machine. The crushed coconut shell of $12.5 \mathrm{~mm}$ size is used as coarse aggregate having specific gravity 1.23 as shown in Fig.-1(b). Crushed CSs are allowed to absorb water for 24 hours and before using, saturated surface dry (SSD) is done as shown in Fig.-1(c). CS has appropriate properties Rasayan J. Chem., 12(3), 1562-1568(2019)

http://dx.doi.org/10.31788/RJC.2019.1235277

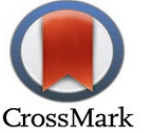


which make it suitable for coarse aggregate with high strength, modular properties can be used promptly in concrete which may satisfy almost all characteristics of the original form of concrete ${ }^{1-2}$.

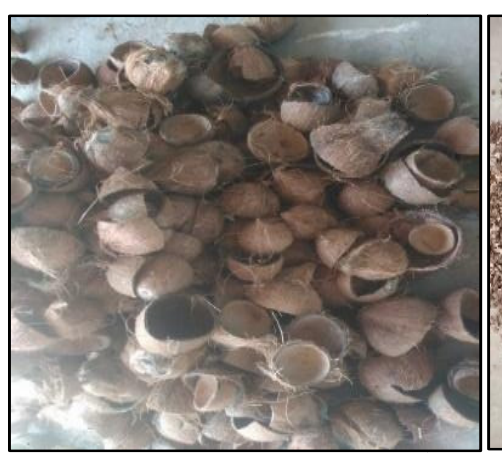

Fig.-1: (a) Collected CS, (b) Crushed CS in size of 12.5mm, (c) CSs in SSD

\section{Granite Powder (GP)}

Granite is an example of an igneous rock. Its various forms are broadly utilized as a construction material. A huge amount of residue and waste materials is produced by granite industries. The waste produced from the granite polishing unit is being subjected to the atmosphere, which causes wellbeing danger. ${ }^{13}$ This GP waste (specific gravity of 2.72) can be utilized well for the preparation of concrete as partial replacement of OPC. The chemical composition of GP in general, is presented in Table- $1 .{ }^{14}$

Table-1: Chemical Composition of $\mathrm{GP}^{14}$

\begin{tabular}{c|c}
\hline Constituent & \% in GP \\
\hline Alumina $\left(\mathrm{Al}_{2} \mathrm{O}_{3}\right)$ & 14.420 \\
\hline Silica $\left(\mathrm{SiO}_{2}\right)$ & 72.040 \\
\hline Iron oxide $\left(\mathrm{Fe}_{2} \mathrm{O}_{3}\right)$ & 1.220 \\
\hline Magnesium Oxide $(\mathrm{MgO})$ & 0.710 \\
\hline Potassium Oxide $\left(\mathrm{K}_{2} \mathrm{O}\right)$ & 4.120 \\
\hline Calcium Oxide $(\mathrm{CaO})$ & 1.820 \\
\hline Sodium Oxide $\left(\mathrm{Na}_{2} \mathrm{O}\right)$ & 3.690 \\
\hline
\end{tabular}

\section{EXPERIMENTAL}

The selected mix ratio for CC was 1:2.22:3.66:0.55 with cement $320 \mathrm{~kg} / \mathrm{m}^{3}$ and that of CSC was 1:1.47:0.65:0.42 with cement $510 \mathrm{~kg} / \mathrm{m}^{3}$, for the target strength M25. The percentage of GP replaced for cement by weight were $0 \%, 5 \%, 10 \%, 15 \%, 20 \%$ and $25 \%$ in order to find the optimum percentage use of GP in both CC and CSC. From these trial mixes, percentage optimization of GP to be used for the replacement of OPC in CC and CSC would be found. Further studies were implemented to find the mechanical properties of CC and CSC with the optimized percentage of GP. Then the results were analyzed and reported.

In this section, the main objectives, scope and the experimental programs were presented.

\section{Objective}

Firstly, it was decided to optimize the percentage use of partial replacement for cement by GP both in CC and CSC in M25 grade of concrete using the trial mixes selected. Then it is proposed to study the mechanical properties (compressive strength, split tensile strength, modulus of elasticity, flexural strength, and impact resistance) of the optimized percentage of GP for cement replacement both in CC and CSC in M25 grade of concrete.

\section{Scope}

GP waste can be overseen by utilizing it both in CC and CSC hence landfill of GP waste can be minimized. Effect of GP in CC and CSC can be found on the mechanical properties of concrete. 
RASĀYAN J. Chem.

Vol. 12 | No. 3 |1562 - 1568| July - September | 2019

\section{Testing Program and Specimen Details}

The required concrete was prepared by mixing in the concrete mixer. Prepared concrete was placed in the respective size and shape of the moulds and compacted on the vibratory table. They were demoulded and kept in a curing tank after 24 hours for respective 3, 7 and 28 days. For every mix, density and workability were measured. The mechanical properties were tested on both CC and CSC with the optimized GP at 3, 7 and 28 days, respectively. Slump cone was used for workability test according to IS $1199(1959)^{15}$ as shown in Fig.-2. As per IS $516(1959),{ }^{16}$ compressive strength was tested on $100 \times 100 \times 100 \mathrm{~mm}$ cubes for a various percentage of GP (Fig.-3). Split tensile strength was tested on $100 \mathrm{~mm}$ diameter and $200 \mathrm{~mm}$ long cylinder for the optimized percentage of GP as per ASTM ${ }^{17}$ as shown in Fig.-4. For the flexural strength test, two-point load method was followed on $100 \times 100 \times 500 \mathrm{~mm}$ beam for the optimized percentage of GP as per ASTM $^{18}$ shown in Fig.-5. Impact resistance test was determined on $63.5 \mathrm{~mm}$ thick and $152.4 \mathrm{~mm}$ diameter as per ACI committee 544.1R-82, for the optimized percentage of GP as shown in Fig.-7. As per IS: 516-1959 ${ }^{16}$, modulus of elasticity of concrete was tested on $100 \mathrm{~mm}$ diameter and $200 \mathrm{~mm}$ height cylinder to acquire stress- stain curve. Contraction of the cylinder at each and every $10000 \mathrm{~N}$ load was recorded during this test as shown in Fig.-8. For all the tests 3, 7 and 28 days tests were carried out and an average of three values was reported and presented.

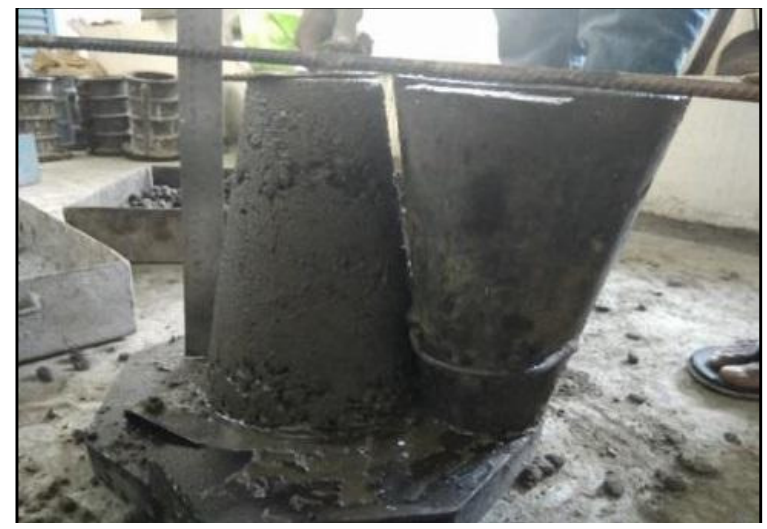

Fig.-2: Slump Cone Test

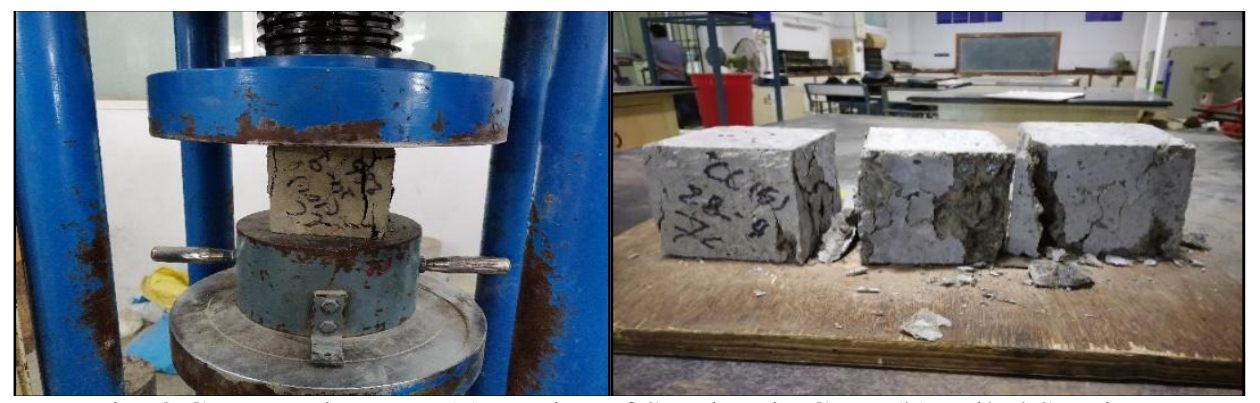

Fig.-3 Compression Test (a) Testing of Specime in CTM (b) Failed Specimens

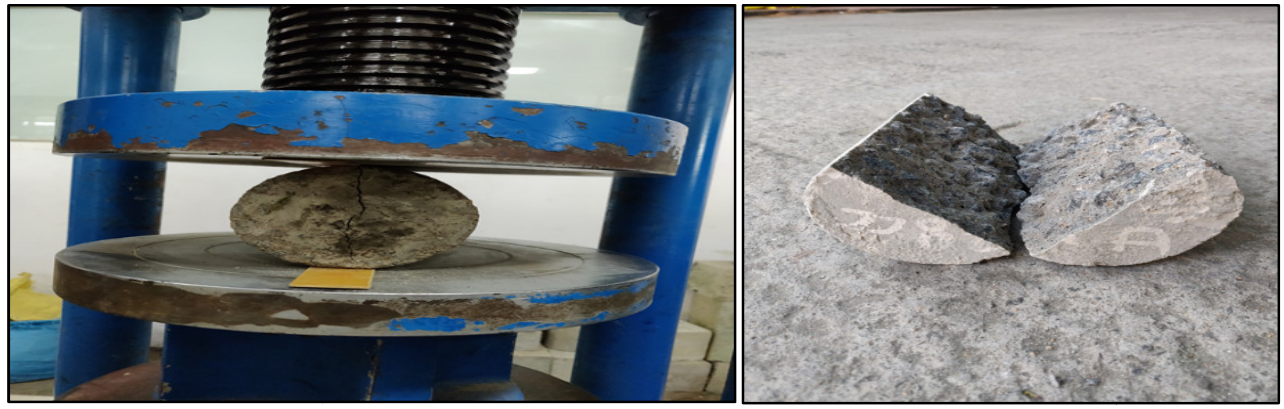

Fig.-4: Split Tensile Test (a) Split Tensile Test in CTM (b) Failed Specimen 
RASĀYAN J. Chem.

Vol. 12 | No. 3 |1562 - 1568| July - September | 2019

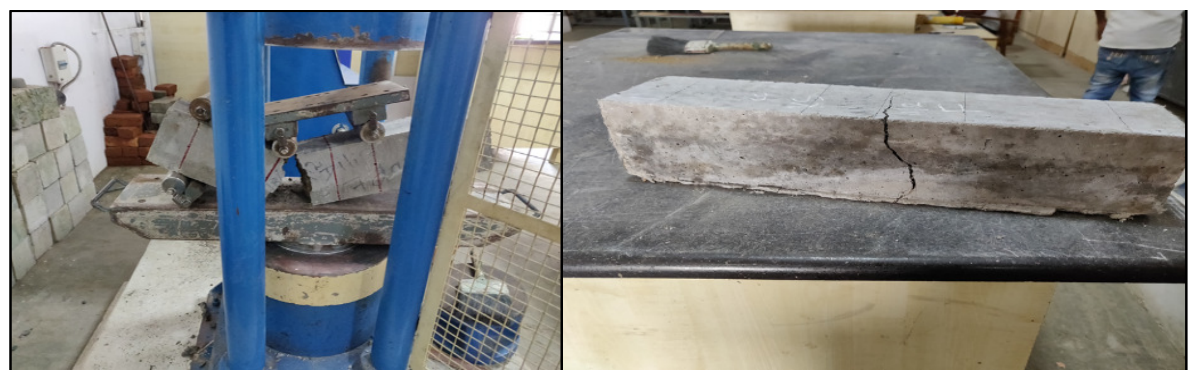

Fig.-5: Flexure Test (a) Flexure Test in CTM (b) Failed Specimen

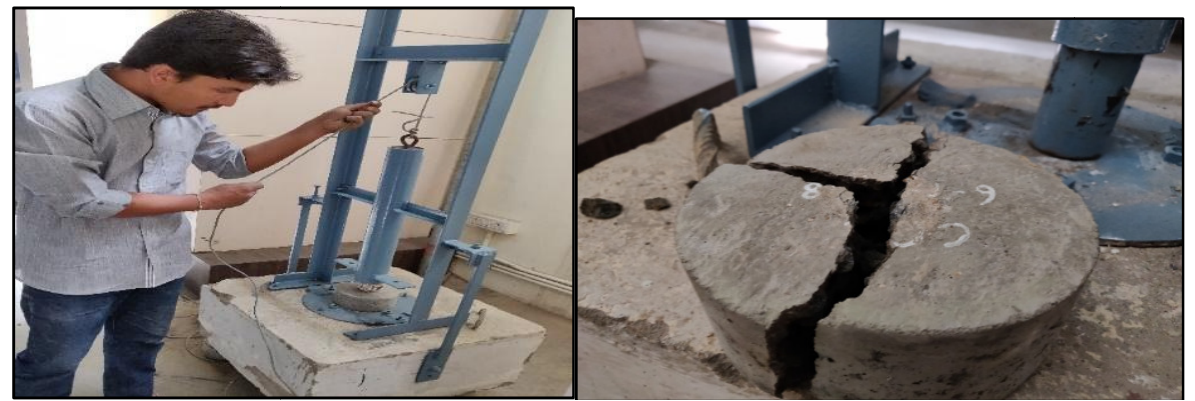

Fig.-6: Impact Resistance Test (a) Testing of the Specimen (b) Failed Specimen

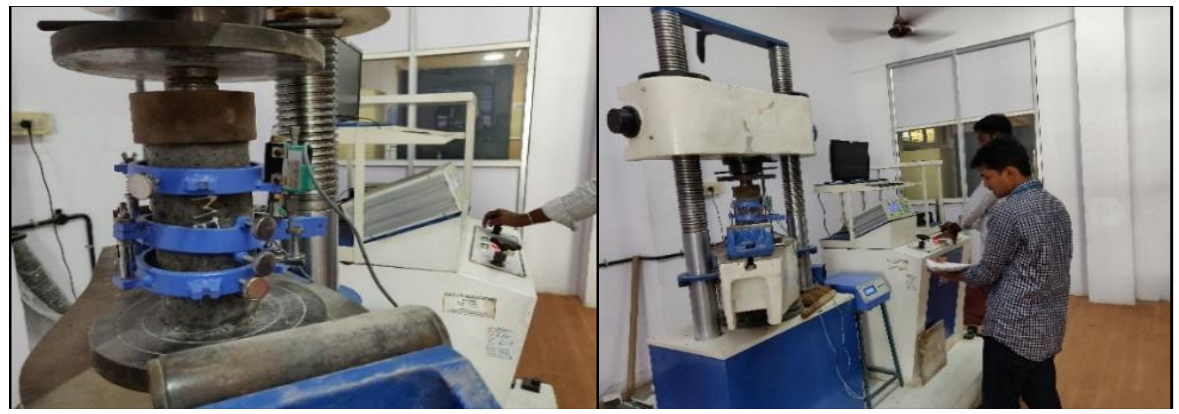

Fig.-7: Testing for Modulus of Elasticity

\section{RESULTS AND DISCUSSION}

For the optimized percentage of partial replacement of GP for OPC, its properties both in a fresh and hardened state such as workability, density and some mechanical properties were tested and discussed for both CC and CSC.

\section{Workability and Density}

The test results carried for the density and workability are listed in Table-2 and 3. As the percentage of GP in both CC and CSC increases, workability increases and density keep on decreases. This pattern was also reported by K. Gunasekaran et al when they used rice husk ash as a replacement for cement ${ }^{5}$.

\section{Compressive Strength}

Compressive strength of both CC and CSC demonstrate that up to $10 \%$ replacement gives good result and decrease as the percentage of GP increases after 10\%. The test result of compressive strength of CC and CSC for $10 \%$ GP is $31.30 \mathrm{~N} / \mathrm{mm}^{2}$ and $30.10 \mathrm{~N} / \mathrm{mm}^{2}$ respectively. Hence, the optimum percentage of GP in CC and CSC is fixed to $10 \%$ as shown in Table-2 and 3.

Table-2: Optimization of CC in GP

\begin{tabular}{c|c|c|c|c|c|c}
\hline \multirow{2}{*}{$\begin{array}{c}\text { \% Replacement } \\
\text { of GP }\end{array}$} & \multirow{2}{*}{$\begin{array}{c}\text { Slump } \\
(\mathrm{mm})\end{array}$} & $\begin{array}{c}\text { Fresh } \\
\text { Concrete }\end{array}$ & $\begin{array}{c}\text { Demoulded } \\
\text { Concrete }\end{array}$ & 3 days & 7 days & 28 days \\
\hline $0 \%$ & 8 & 2616 & 2432 & 13.73 & 19.17 & 28.51 \\
\hline
\end{tabular}


RASĀYAN $J$. Chem.

Vol. 12 | No. 3 |1562 - 1568| July - September | 2019

\begin{tabular}{c|l|l|l|l|l|l}
\hline $5 \%$ & 7 & 2591 & 2421 & 16.77 & 20.53 & 29.30 \\
\hline $10 \%$ & 7 & 2479 & 2403 & 18.86 & 21.70 & 31.30 \\
\hline $15 \%$ & 7 & 2440 & 2378 & 17.90 & 20.36 & 30.61 \\
\hline $20 \%$ & 6 & 2395 & 2334 & 17.23 & 20.14 & 29.12 \\
\hline $25 \%$ & 6 & 2284 & 2231 & 16.43 & 19.97 & 28.23 \\
\hline
\end{tabular}

Table-3: Optimization of CC in GP

\begin{tabular}{|c|c|c|c|c|c|c|}
\hline \multirow{2}{*}{$\begin{array}{c}\text { \% Replacement } \\
\text { of GP }\end{array}$} & \multirow[b]{2}{*}{$\begin{array}{l}\text { Slump } \\
(\mathrm{mm})\end{array}$} & \multicolumn{2}{|c|}{ Density $\left(\mathrm{kg} / \mathrm{m}^{3}\right)$} & \multicolumn{3}{|c|}{ Compressive Strength $\left(\mathrm{N} / \mathrm{mm}^{2}\right)$} \\
\hline & & $\begin{array}{c}\text { Fresh } \\
\text { Concrete }\end{array}$ & $\begin{array}{c}\text { Demoulded } \\
\text { Concrete }\end{array}$ & 3 days & 7 days & 28 days \\
\hline $0 \%$ & 7 & 2091 & 1985 & 12.10 & 18.13 & 28.32 \\
\hline $5 \%$ & 7 & 1995 & 1854 & 13.43 & 18.44 & 29.20 \\
\hline $10 \%$ & 6 & 1974 & 1846 & 16.80 & 19.97 & 30.10 \\
\hline $15 \%$ & 6 & 1983 & 1839 & 16.57 & 19.36 & 29.92 \\
\hline $20 \%$ & 6 & 1977 & 1824 & 16.44 & 19.12 & 28.36 \\
\hline $25 \%$ & 6 & 1963 & 1806 & 15.73 & 18.79 & 27.32 \\
\hline
\end{tabular}

\section{Split Tensile Strength}

After 28 days curing, the split tensile strength was $2.61 \mathrm{~N} / \mathrm{mm}^{2}$ (8.34\% of compressive strength) and 2.22 $\mathrm{N} / \mathrm{mm}^{2}$ (7.8\% of compressive strength) for CC and CSC respectively. For $10 \%$ of GP in both CC and CSC, the split tensile strength at 3, 7 and 28 days is demonstrated in Fig.-8.

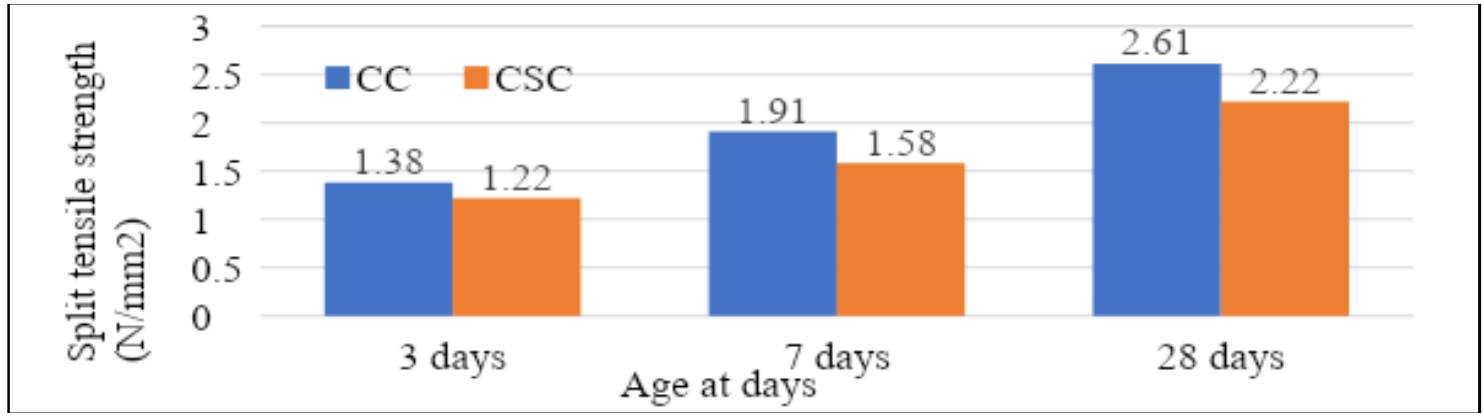

\section{Flexural Strength}

Fig.-8: Split Tensile Strength of CC and CSC

The flexural strength of concrete is always between 10 to $15 \%$ of compressive strength ${ }^{3} .28$ days flexural strength for CC and CSC is $4.20 \mathrm{~N} / \mathrm{mm}^{2}$ (14.38\% of compressive strength) and $3.25 \mathrm{~N} / \mathrm{mm}^{2}$ (10.80\% of compressive strength) respectively. For $10 \%$ of GP in both CC and CSC, 3, 7 and 28 days flexural strength is illustrated in Fig.-9.

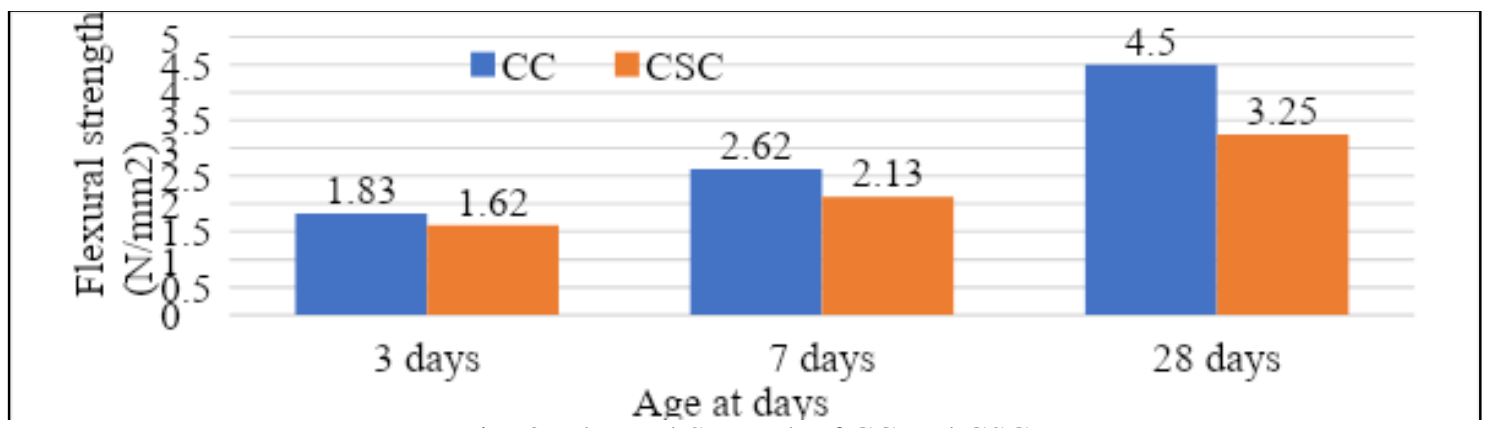

\section{Impact Resistance}

Fig.-9: Flexural Strength of CC and CSC

Impact resistance test result at 28 days for $\mathrm{CC}$ shows, initial crack took place at 19 numbers of blows and final crack occurred at 27 number of blows. Similarly, for CSC mix, an initial crack occurred at 22 blows 
and final crack at 36 blows. Due to the fibrous nature of CS aggregate, CSC withstands a higher number of blows than CC. Figure 10 shows the impact resistance at 3,7 and 28 days.

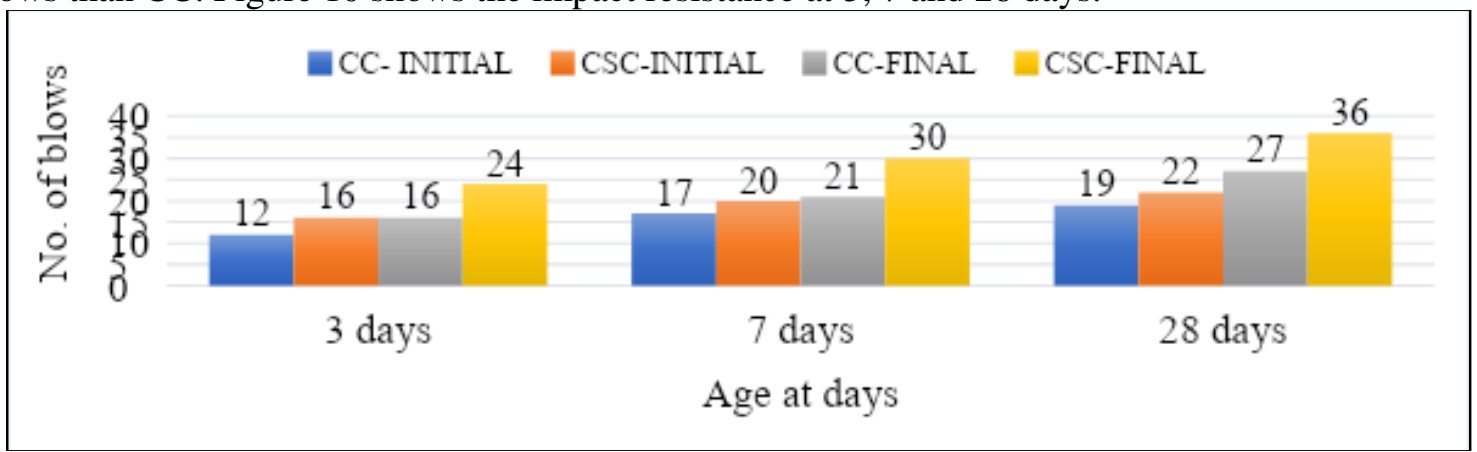

Fig.-10: Impact Resistance Results for CC and CSC

\section{Modulus of Elasticity}

As per IS 516-1959, modulus of elasticity of concrete is attained from the stress-strain curve. The test result shows that modulus of elasticity at $50 \%$ of the compressive strength of CC and CSC is 25156 $\mathrm{N} / \mathrm{mm}^{2}$ and $12406 \mathrm{~N} / \mathrm{mm}^{2}$ respectively for $10 \%$ replacement of GP. CC shows a higher value than that of CSC.The stress-stain curve for CC and CSC is displaced in Fig.-11.

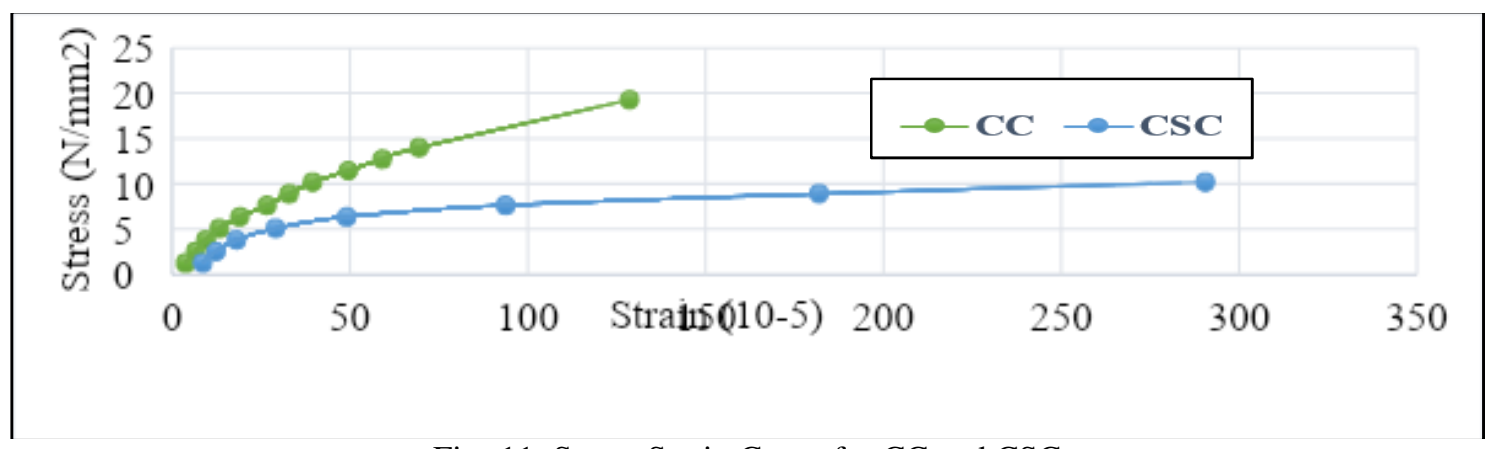

Fig.-11: Stress-Strain Curve for CC and CSC

\section{CONCLUSION}

- From the present research work carried out, partial replacement of GP can be.

- Workability of concrete increases after the replacement of GP in OPC.

- The density of concrete keep on decreasing with increasing percentage replacement of GP in CC and CSC.

- Based on the compressive strength of different percentage replacement of GP in bothy CC and CSC at 28 days, the optimization of $10 \%$ of GP is achieved.

- The split tensile strength for CC and CSC at 28 days is $2.61 \mathrm{~N} / \mathrm{mm}^{2}\left(8.34 \%\right.$ of $31.30 \mathrm{~N} / \mathrm{mm}^{2}$ compressive strength) and $2.22 \mathrm{~N} / \mathrm{mm}^{2}\left(7.38 \%\right.$ of $30.10 \mathrm{~N} / \mathrm{mm}^{2}$ compressive strength) respectively.

- The flexural strength for CC and CSC at 28 days is $4.50 \mathrm{~N} / \mathrm{mm}^{2}$ and $3.25 \mathrm{~N} / \mathrm{mm}^{2}$ which is $14.38 \%$ and $10.80 \%$ of its respective compressive strength respectively.

- When contrasted with CC, the impact resistance of CSC is found higher.

- The modulus of elasticity for CC and CSC at 28 days is $25156 \mathrm{~N} / \mathrm{mm}^{2}$ and $12406 \mathrm{~N} / \mathrm{mm}^{2}$ respectively.

- These all investigation demonstrate that, the $10 \%$ replacement of cement with GP upgrade the mechanical properties of concrete regardless of CC and CSC.

\section{REFERENCES}

1. K. Gunasekaran, S. Prakash Chandar, K. Prasanth and G. Senthil Kumar, Rasayan Journal of Chemistry, 10, 528(2017), DOI:10.7324/RJC.2017.1021636

2. S. Karthik and T. Saranya, Rasayan Journal of Chemistry, 10, 415(2017), DOI:10.7324/RJC.2017.1021642 
RASĀYAN J. Chem.

Vol. 12 | No. 3 |1562 - 1568| July - September | 2019

3. M. Prakash and P. Narayanaswamy, Rasayan Journal of Chemistry, 10, 442(2017), DOI:10.7324/RJC.2017.1021689

4. K. Gunasekaran, R. Annadurai and P. S. Kumar, Construction and Building Materials, 28,208(2012), DOI: $10.1016 /$ j.matdes.2013.03.022

5. M. Mohamed Barveen and K. Gunasekaran, International Journal of Civil Engineering and Technology, 9,264(2018)

6. S. A. Abukersh, C. A. Fairfield, Construction and Building Materials, 25,4088(2011), DOI: 10.1016/j.conbuildmat.2011.04.047

7. Baboo Rai, H. Khan Naushad, Abhishek Kr, S. Tabin Rushad and S. K. Duggal, International Journal of Civil and Structural Engineering, 4,827 (2011)

8. T. Felix Kala and P. Partheeban, Indian Journal of Science and Technology, 3,311(2010)

9. P. A. Shirulea, A. Rahmanb and D. Rakesh, International Journal of Advanced Engineering Research and Studies, 1,175(2012)

10. IS 12269:1987, Indian Standard Ordinary Portland Cement, 53 Grade-Specifications, New Delhi, (Reaffirmed January 1999)

11. IS 383:2016, Indian Standard Specification for Coarse and Fine Aggregates for ConcreteSpecification, New Delhi (Third Revision, January 2016)

12. IS 456:2000, Indian Standard for Plain and Reinforced Concrete-Code of Practice, New Delhi, (2000)

13. T. Felix Kala, International Journal of Engineering and Science, 2,36(2013)

14. G. Prince Arulraj, A. Adin, and T. S. Kannan, Engineering Science and Technology, 3,193(2013), DOI: $10.22214 /$ ijraset.2018.4542

15. IS 1199(1959), Indian Standard Methods of Sampling and Analysis of Concrete, New Delhi, (Reaffirmed 2004)

16. IS 516:1959, Indian Standard Methods of Tests for Strength of Concrete, New Delhi, (Reaffirmed 2004)

17. ASTM-C496/C496M-11, Standard Test Method for Splitting Tensile Strength of Cylindrical Concrete Specimens, Annual Book of ASTM Standards.

18. ASTM-C78-84, Standard Test Method for Flexural Strength of Concrete, Annual Book of ASTM Standards.

[RJC-5277/2019] 